\title{
Konsumsi Fast Food dan Aktivitas Fisik dengan Kejadian Sindrom Metabolik Di RSUD Prof. Dr. Margono Soekarjo Purwokerto
}

\author{
Pugud Samodro ${ }^{1}$, Nurul Hasna Zulfannisa ${ }^{2}$ Agus Prastowo ${ }^{3}$, Nunung Wahyuni ${ }^{3}$ \\ ${ }^{1}$ Bagian Penyakit Dalam FK Universitas Jenderal Soedirman Purwokerto, Jl. Dr.Gumbreg No. 1 Mersi \\ Purwokerto 53112 \\ 2 Jurusan Gizi Poltekkes Kemenkes Semarang, Jl. Wolter Monginsidi No.115, Pedurungan Tengah, Kec. \\ Pedurungan, Kota Semarang, Jawa Tengah 50192 \\ ${ }^{3}$ RSUD Prof Dr. Margono Soekarjo, Jl. Dr. Gumbreg No.1, Kebontebu, Berkoh, Kec. Purwokerto Sel., Kabupaten \\ Banyumas, Jawa Tengah 53146
}

Korespondensi penulis : pras_cakeb@yahoo.co.id

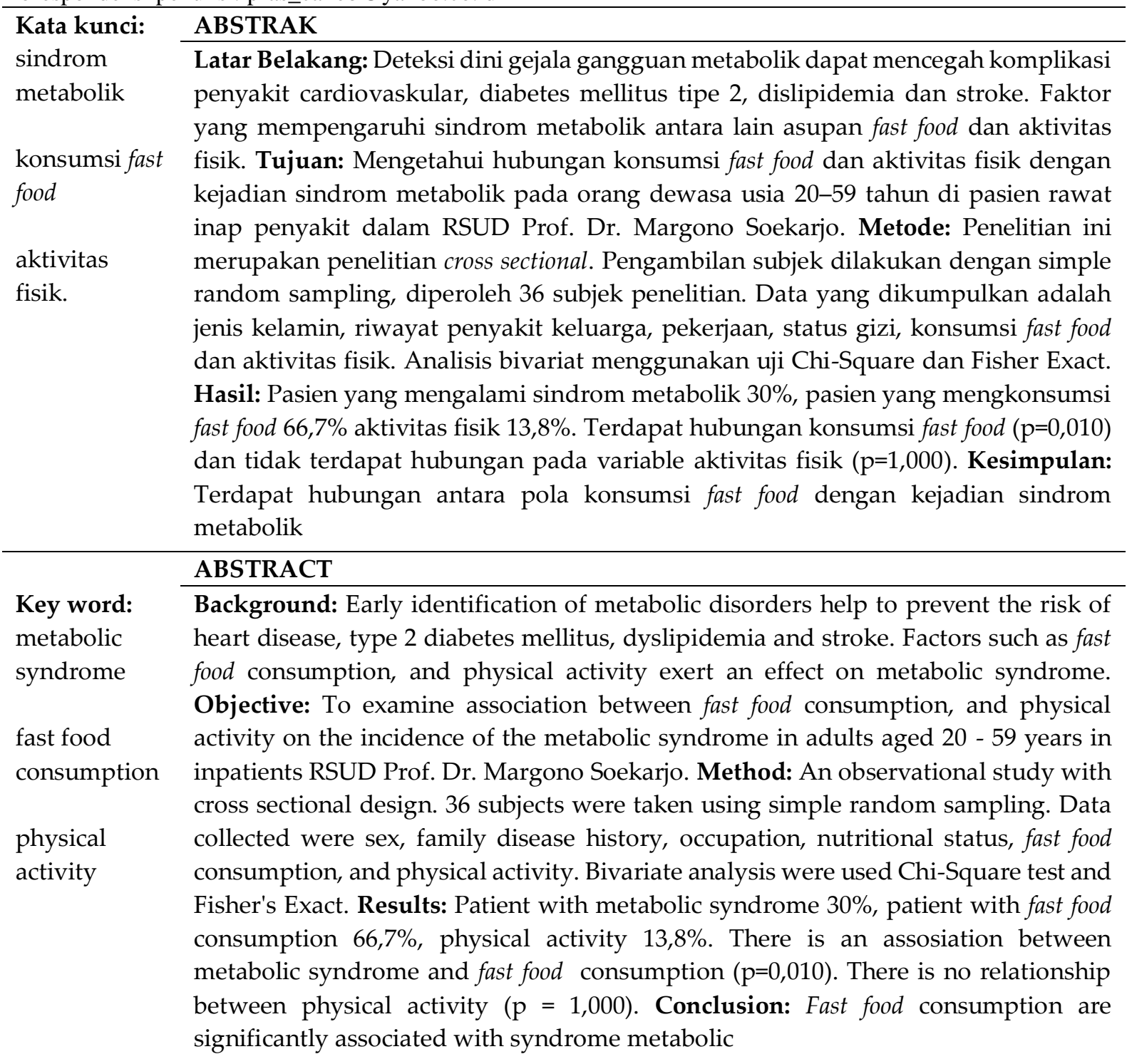




\section{Pendahuluan}

Sindrom metabolik adalah sekumpulan gejala yang meliputi peningkatan glukosa darah, peningkatan trigliserida, hipertensi dan obesitas. Pencegahan komplikasi sindroma metabolik seperti penyakit jantung, diabetes melitus tipe 2, dislipidemia dan stroke dapat dilakukan dengan mengenali sedinini mungkin gejala dan tanda sindroma metabolik. ${ }^{1,2,5}$

Riset Kesehatan Dasar (2018) di Indonesia menunjukkan prevalensi penyakit terkait sindrom metabolik semakin meningkat seperti Diabetes Mellitus (DM) 2,0\% paling banyak terjadi pada wanita usia 55 - 64 tahun yang tinggal di perkotaan, penyakit jantung 1,5\% yang banyak terjadi pada wanita 75 tahun keatas, hipertensi $34,1 \%$, berat badan lebih $13,6 \%$, obesitas $21,8 \%$, dan obesitas sentral $31,0 \% .^{4}$

Selain asupan zat gizi, aktivitas fisik juga berperan penting terhadap kejadian sindrom metabolik. Berdasarkan data riskesdas 2018 terjadi peningkatan dalam 5 tahun terakhir terkait aktivitas fisik yang kurang, tercatat pada tahun 2013 proporsi aktivitas kurang 26,1\% sedangkan pada tahun 2018 33,5\%. Hal ini di dukung oleh sebuah penelitian yang menyatakan orang dewasa obesitas kurang aktif secara fisik dibandingkan orang dewasa dengan status gizi normal. ${ }^{4,8}$

Konsumsi fast food juga merupakan salah satu pemicu obesitas pada remaja. Terdapat hubungan signifikan antara konsumsi fast food, jajanan selingan dengan obesitas. Penelitian lainnya yang dilakukan di Semarang juga menunjukkan hubungan yang signifikan antara konsumsi fast food dan kebiasaan jajan mempunyai risiko 3.2x untuk obesitas. Konsumsi fast food dengan frekuensi sering, berhubungan dengan peningkatan indeks massa tubuh (IMT).9,10,11

Studi pendahuluan di RSUD Prof. Dr. Margono Soekarjo Purwokerto di ruang rawat penyakit dalam dewasa menunjukkan $70 \%$ dari 150 penderita masuk katagori sindroma metabolik berdsarkan NCEP ATP III. Penelitian ini bertujuan untuk mengetahui hubungan pola konsumsi fast food dan aktivitas fisik dengan sindrom metabolik pada orang dewasa usia 20 - 59 tahun di pasien rawat inap penyakit dalam RSUD Prof. Dr. Margono Soekarjo Purwokerto.

\section{Metode}

Penelitian ini termasuk studi observasional dengan rancangan cross sectional. Penelitian dilakukan pada periode April-Mei 2019 dengan jumlah subjek penelitian berdasarkan rumus besar sampel sebesar 36 pasien.

Subjek pada penelitian ini yaitu perempuan dan laki-laki berusia 20 - 59 tahun yang bersedia berperan dalam penelitian ini, dapat berkomunikasi dengan jelas, tidak mengalami disabilitas, tidak oedema dan atau acites, tidak DM kronis, tidak terdapat penyakit penyerta seperti infeksi, kanker, dyspepsia, gagal ginjal kronik, tumor, stroke, dan kondisi hamil. Pengambilan subjek penelitian menggunkan metode simple random sampling sesuai kriteria inklusi.

Variable bebas pada penelitian ini adalah konsumsi fast food dan aktivitas fisik, sedangkan variabel terikatnya adalah kejadian sindrom metabolik. Instrumen yang digunakan terdiri dari formulir persetujuan, formulir identitas subjek, formulir Food Frequency Quesionare konsumsi makanan cepat saji (fast food) dan formulir formulir Baecke yang digunakan untuk mengukur aktivitas fisik. Pengkatagorian konsumsi fast food dan aktivitas fisik menggunakan cut off point sebesar 2.4 dan 3.6 dari nilai rerata. Penentuan sindrom metabolik dari hasil pengukuran BB yang diukur menggunakan timbangan digital dan TB estimasi berdasarkan ulna dan lingkar 
perut yang diukur menggunakan metlin, hasil pengukuran data laboratorium (HDL, trigliserida, GDP) menggunakan data rekam medis rumah sakit.

Analisis bivariat digunakan untuk mengetahui hubungan antara variabel bebas dan variabel terikat yang diuji dengan menggunakan uji chi square gengan tingkat kepercayaan sebesar $95 \%$.

\section{Hasil Dan Pembahasan}

\section{Karakteristik Subjek}

Hasil skrining awal melibatkan 150 pasien di bangsal penyakit dalam RSUD Prof. Dr. Margono Soekarjo Purwokerto yang menunjukkan kategori sindrom metabolik berdsarkan NCEP ATP III terdapat 105 (70\%) pasien tidak sindrom metabolik dan 45 (30\%) pasien mengalami sindrom metabolik. Diperoleh subjek penelitian sebanyak 36 orang. Pada subjek penelitian didapatkan sebanyak $6(16,7 \%)$ pasien tidak sindrom metabolik terdiri dari $5(83,3 \%)$ laki-laki dan $1(16,7 \%)$ perempuan, serta $30(83,3 \%)$ pasien sindrom metabolik, yang terdiri dari $13(41,7 \%)$ laki-laki dan 17 (58,3\%) perempuan.

Tabel 1. Nilai minimum, maksimum, rerata dan standar deviasi komponen sindrom metabolik pada subjek penelitian $(n=36)$

\begin{tabular}{lcccc}
\hline \multicolumn{1}{c}{ Komponen SM } & Min & Maks & Rerata & SD \\
\hline Lingkar Pinggang (cm) & 90 & 170 & 102,7 & 16,69 \\
Tekanan darah (mmHg) & & & & \\
- Sistolik & 100 & 206 & 147,25 & 22,1 \\
- Diastolik & 70 & 110 & 89,86 & 7,8 \\
Gula darah puasa (mg/dL) & 80 & 505 & 201,3 & 87,2 \\
Status Gizi & 25,3 & 46,8 & 29,1 & 4,6 \\
\hline Keterangan: SD = Standar Deviasi: min = minimum: maks = maksimum & &
\end{tabular}

Keterangan: $\mathrm{SD}=$ Standar Deviasi; $\mathrm{min}=$ minimum; maks = maksimum

Nilai maksimum lingkar pinggang adalah $170 \mathrm{~cm}$. Rerata tekanan darah dengan nilai maksimum sistolik $206 \mathrm{mmHg}$ dan diastolik adalah $110 \mathrm{mmHg}$. Nilai maksimum gula darah puasa mencapai $505 \mathrm{mg} / \mathrm{dL}$.

Kejadian sindrom metabolik sebagian besar banyak ditemukan pada perempuan, hal ini dikarenakan sebagian besar subjek penelitian di bangsal penyakit dalam RSUD Prof. Dr. Margono Soekarjo Purwokerto adalah perempuan. Sebenarnya laki-laki lebih rentan mengalami obesitas sentral dikarenakan laki-laki memiliki simpanan lebih banyak dalam abdomen. Lemak intra abdomen sensitif terhadap stimulus pemecahan lemak yang berkapasitas lebih besar untuk menghasilkan asam lemak bebas. Lemak subkutan lebih resisten terhadap pemecahan lemak dan lebih terproteksi dari fluktuasi sehari-hari. Hal ini yang menngakibatkan sindroma metabolik lebih banyak terjadi pada laki-laki daripada perempuan. ${ }^{13}$

Penelitian ini menunjukkan rerata lingkar pinggang, tekanan darah, serta gula darah puasa dan status gizi berdasarkan indeks masa tubuh diketahui tinggi (tabel 2). Lingkar pinggang yang tinggi itu menunjukkan penimbunan jaringan lemak abdomen atau lebih dikenal dengan obesitas sentral. Obesitas sentral dianggap sangat berhubungan dengan kejadian sindroma metabolik. Lemak di daerah viseral lebih bersifat lipolitik dan penyebab dari resistensi insulin serta hiperinsulinemia. Keadaan tersebut mengakibatkan hipertensi dan dislipidemia. ${ }^{14,15}$ Jaringan lemak merupakan organ endokrin aktif dan berkorelasi positif terhadap kadar proinflamasi adipocytokines, Interleukin-6 (IL-6), tumor necrosis factor- $\alpha$ (TNF $\alpha$ ), dan leptin, yang tidak ada korelasinya dengan kadar adiponectin yang berfungsi mengatur sensitifitas terhadap insulin dan menaikkan aktivitas antiinflamasi. ${ }^{16}$ 
Penelitian lain menunjukkan faktor risiko sindrom metabolik pada remaja adalah obesitas sentral (55\%), HDL-hipokolesterol (35,5\%), hipertensi (21\%), hipertrigliserida (18,5\%), dan hiperglikemia(2\%). ${ }^{14} \mathrm{Hal}$ ini membuktikan bahwa obesitas sentral memiliki presentase tertinggi di antara komponen sindroma metabolik sehingga ditengarai sebagai faktor risiko utama sindroma metabolik. Penyebab obesitas sebagai faktor risiko sindrom metabolik sangat kompleks dan multifaktor meliputi faktor genetik dan lingkungan. ${ }^{17,18}$

\section{Konsumsi Fast Food dan Aktivitas Fisik pada Subjek}

Tabel 2. Nilai minimum, maksimum, rerata dan standar deviasi variabel bebas pada subjek penelitian

\begin{tabular}{|c|c|c|c|c|}
\hline \multirow{2}{*}{$\begin{array}{c}\text { Komponen variabel } \\
\text { bebas }\end{array}$} & \multicolumn{2}{|c|}{ Tidak SM $(n=6)$} & \multicolumn{2}{|c|}{$\mathrm{SM}(\mathrm{n}=30)$} \\
\hline & $\begin{array}{l}\text { Min - } \\
\text { Maks }\end{array}$ & $\begin{array}{c}\text { Rerata } \pm \\
\text { SD }\end{array}$ & $\begin{array}{l}\text { Min - } \\
\text { Maks }\end{array}$ & Rerata \pm SD \\
\hline Pola konsumsi fast food & $0,89-3,5$ & $2,4 \pm 7,07$ & $0,43-4,1$ & $2,98 \pm 4,78$ \\
\hline Aktivitas fisik & $1,9-5,61$ & $3,6 \pm 0,77$ & $1,2-6,9$ & $4,0 \pm 1,3$ \\
\hline
\end{tabular}

Tabel 2 menunjukkan rerata pola konsumsi fast food, dan aktivitas fisik pada subjek sindrom metabolik. Di ketahui juga rerata konsumsi serat lebih tinggi pada subjek sindrom metabolik. Sedangkan untuk konsumsi fast food lebih tinggi pada subjek sindrom metabolik juga.

\section{Pola Konsumsi Fast Food, dan Aktivitas Fisik dengan Kejadian Sindrom Metabolik}

Tabel 3. Hubungan pola konsumsi fast food dan aktivitas fisik dengan kejadian sindrom metabolik

\begin{tabular}{|c|c|c|c|c|c|c|}
\hline \multirow{2}{*}{ Variabel } & \multicolumn{2}{|c|}{ Tidak SM } & \multicolumn{2}{|c|}{ SM } & \multirow{2}{*}{ Total (\%) } & \multirow[b]{2}{*}{$P$} \\
\hline & $\mathrm{n}$ & $\%$ & $\mathrm{n}$ & $\%$ & & \\
\hline \multicolumn{7}{|c|}{ Konsumsi fast food } \\
\hline - Sering & 1 & 4,2 & 23 & 95,8 & 100 & 0,010 \\
\hline - Jarang & 5 & 41,7 & 7 & 58,3 & 100 & \\
\hline \multicolumn{7}{|l|}{ Aktivitas Fisik } \\
\hline - Ringan & 5 & 16,1 & 26 & 83,9 & 100 & 1,000 \\
\hline - Sedang & 1 & 20 & 4 & 80 & 100 & \\
\hline
\end{tabular}

Diketahui dari tabel 3 bahwa terdapat hubungan antara pola konsumsi fast food dengan kejadian sindrom metabolik dengan nilai $\mathrm{p}<0,05$ dan aktivitas fisik tidak terdapat hubungan dengan kejadian sindrom metabolik dengan nilai $p>0,05$. Jika dilihat dari hasil tabel diatas menunjukkan subjek sindrom metabolik maupun tidak sindrom metabolic sebagian besar konsumsi fast food masuk ke dalam kategori sering dan aktivitas fisk masuk ke dalam kategori ringan. Adapun konsumsi fast food yang termasuk kategori sering didapatkan lebih tinggi pada subjek tidak sindrom metabolik.

\section{Hubungan Konsumsi Fast Food, dan Aktivitas Fisik dengan Kejadian Sindrom Metabolik}

Hasil analisis menunjukkan terdapat hubungan antara pola konsumsi fast food dengan kejadian sindrom metabolik dengan $p=0,010$ (tabel 3). Hal ini sejalan dengan penelitian yang 
dilakukan oleh Suhaema dan Herta menunjukkan terdapat hubungan yang signifikan antara pola konsumsi sayur dan buah, frekuensi konsumsi makanan manis, asin, berlemak, lauk hewani yang diawetkan, penggunaan penyedap, dan mi instan dengan kejadian sindrom metabolik pada usia produktif. ${ }^{26}$ Sebuah penelitian yang dilakukan oleh Pramono (2007) menunjukkan bahwa terdapat hubungan signifikan antara konsumsi fast food, jajanan selingan dengan obesitas. Penelitian lainnya yang dilakukan oleh Pramono dan Sulchan (2014) juga menunjukkan hubungan yang signifikan antara konsumsi fast food $(p=0,048)$ dan kebiasaan jajan $(p=0,003)$ dengan obesitas. ${ }^{49,10}$ Sebuah studi cross sectional juga menunjukkan bahwa konsumsi fast food dengan frekuensi sering, berhubungan dengan peningkatan indeks massa tubuh (IMT). ${ }^{11}$

Menurut Arunika (2017) di era globalisasi, kuantitas dan kualitas makanan yang dipilih adalah makanan yang tersedia secara instan, seperti fast food, junk food, makanan ringan, ataupun jajanan sekolah yang lebih mengutamakan rasa enak tanpa mempertimbangkan jumlah kalori yang terkandung, apakah sesuai dengan kebutuhan seharusnya. ${ }^{22}$ Menurut Bruscato (2010) makanan fast food merupakan makanan yang tinggi lemak jenuh dan karbohidrat, konsumsi lemak jenuh dapat mempengaruhi pembentukan lemak visceral. Peningkatan lemak visceral memberikan kontribusi terhadap sindrom metabolik. ${ }^{40}$ Ada banyak faktor yang mempengaruhi status gizi remaja, di antaranya adalah aktivitas fisik, kesukaan, malabsorbsi, alergi, intoleransi zat makanan tertentu, tingkat stress/depresi, penyakit kronis yang diderita, proses metabolisme, keturunan, keseimbangan hormon, tingkat ekonomi, tingkat pengetahuan ${ }^{29}$

Hasil analisis menunjukkan tidak terdapat hubungan antara aktivitas fisik dengan kejadian sindrom metabolik dengan $p=1,000 ; \mathrm{OR}=0,714 ; 95 \% \mathrm{CI}=0,103-4,977$. Walaupun tidak menunjukkan hubungan yang signifikan tetapi rerata aktivitas fisik pada subjek penelitian yang sindrom metabolik masuk ke dalam kategori sering yaitu $(4,0 \pm 1,3)$ dibandingkan dengan yang tidak sindrom metabolik $(3,6 \pm 0,77)$. Hal tersebut sejalan dengan penelitian yang dilakukan Lussi dan Fitriana, (2016) menunjukkan tidak ada hubungan yang signifikan antara aktivitas fisik, kebiasaan olahraga dengan kejadian sindrom metabolik $(p=0,324) .{ }^{33}$

Berbeda dengan penelitian yang dilakukan oleh Arunika, (2017) subjek dengan kategori aktivitas ringan $23.4 \%$, kategori sedang $51.0 \%$, dan kategori aktivitas berat $25.5 \%$. Terdapat hubungan yang bermakna antara status overweight/obesitas dengan aktivitas fisik $(\mathrm{p}=0,031) .{ }^{24}$

Aktivitas fisik merupakan faktor yang menentukan perkembangan sindrom metabolik sebab mempengaruhi obesitas dan distribusi lemak serta proses inflamasi yang berhubungan dengan risiko penyakit kardiovascular pada usia lanjut. ${ }^{38,39}$ Aktivitas fisik tingkat moderat dapat menurunkan tekanan darah secara signifikan pada pasien hipertensi esensial ringan hingga sedang. Selain itu aktivitas fisik juga berperan pada peningkatan sensitivitas reseptor insulin sehingga mencegah resistensi insulin. ${ }^{40,41}$

\section{Kesimpulan}

Terdapat hubungan antara pola konsumsi fast food dengan sindrom metabolik dan tidak terdapat hubungan antara pola konsumsi dan aktivitas fisik dengan kejadian sindrom metabolik. Disarankan pada orang dewasa untuk menghindari fast food karena dapat menyebabkan penyakit sindroma metabolik. Konsumsi makanan lebih baik dalam bentuk makanan olahan segar.

\section{Referensi}

1. Widjaya A, et al. Obesitas dan sindrom Metabolik. Forum Diagnosticum. 2004(4): 1-16. 
2. Grundy SM, Brewer HB, Cleeman JL, Smith SC, Lenfant C. Defnition of metabolic syndrome. Report of National Heart, Lung and Blood Institute/American Heart Association conference on scientifc issues related to defnition. Circulation 2004; 109 : 433-8.

3. M. A. Bimandama dan Tri Umiana. Hubungan Sindrom Metabolik dengan Penyakit Kardiovaskular. Majority. 2016 ; Volume 5 : Nomor 2

4. Kementrian Kesehatan Badan Penelitian dan Pengembangan Kesehatan. Hasil utama Riskesdas 2018. 2018.

5. Pan, Y. and C. A. Pratt. Metabolic syndrome and Its Association With Diet And Physical Activity In US Adolescents. J Am Diet Assoc. 2008; 108(2): 276-286; discussion 286.

6. Executive Summary of The Third Report of The National Cholesterol Education Program (NCEP) Expert Panel on Detection, Evaluation, And Treatment of High Blood Cholesterol In Adults (Adult Treatment Panel III), JAMA 2001; 285:2486-97.

7. Lorenzo C, Williams K, Hunt KJ, and Haffner SM. The National Cholesterol Education Program-Adult Treatment Panel III, International Diabetes Federation, and World Health Organization definitions of the metabolic syndrome as predictors of incident cardiovascular disease and diabetes. Diabetes Care. 2007;30:8-13.

8. Joshua A Bell., et al. Healthy Obesity and Objective Physical Activity. Am J Clin Nutr. 2015 ; $102: 268-75$.

9. Pramono A., (2007). Hubungan antara tingkat aktivitas fisik, kontribusi asupan energy dari fast food dan kebiasaan jajan dengan obesitas pada remaja. KTI Nutrition science program.

10.Pramono, A., \& Sulchan, M. (2014). Kontribusi makanan jajan dan aktivitas fisik terhadap kejadian obesitas pada remaja di kota Semarang. Jurnal Gizi Indonesia, 2(2), 59-64.

11.Braithwaite, I., Stewart, A.W., Hancox, R.J., Beasley, R., Murphy, R., \& Mitchell, E.A. (2014). Fast-food consumption and body mass index in children and adolescents: an international cross-sectional study. Biomed Journal, 4, 1-10.

12.Marice Sihombing dan Dwi Hapsari T. Faktor Risiko Sindrom Metabolik pada Orang Dewasa di Kota Bogor. Penelitian Gizi dan Makanan. 2015. Vol. 38 (1): 21 - 30.

13. Yunieswati W, Briawan D. Status antropometri dengan beberapa indikator pada mahasiswa TPB-IPB. J. Gizi Pangan, November 2014, 9(3):181-186

14. Ni Komang Wiardani dan I Wayan Juni Arsana. Kejadian Sindrom Metabolik Berdasarkan Status Obesitas pada Masyarakat Perkotaan di Denpasar. Jurnal Ilmu Gizi, Volume 2 Nomor 2, Agustus 2011: 129-138.

15.Kamso S. Metabolic syndrome in the Indonesian Elderly Medical Journal of Indonesia. 2007;16.

16.Anjana M, Sandeep S, Deepa R, Vimaleswaran K, Farooq S, Mohan V. Visceral and Central Abdominal Fat and Anthropometry in Relation to Diabetes in Asian Indians. Diabetes Care. 2004;27:2948.

17.Rizzo ACB, Goldberg TBL, Silva CC, Kurokawa CS, Corrente JE. Metabolic syndrome risk factors in overweight, obese, and extremely obese brazilian adolescents. Nutritional Journal 2013; 12:19.

18.Despres JP, Lemieux I, Bergeron J, Pibarot P, Mathieu P, Larose E, et al. Abdominal obesity and the metabolic syndrome: contribution to global cardiometabolic risk. Arteriosclerosis, thrombosis, and vascular biology. 2008;28(6):1039-49.

19.Nurmasari W. Asupan Lemak Jenuh dan Serat pada Remaja Obesitas Kaitannya dengan Sindrom Metabolik. 2016. Jurnal Gizi Klinik Indonesia ; Vol. 12, No. 4 : 131 - 137. 
20.Pan, Y. and C. A. Pratt. Metabolic syndrome and Its Association With Diet And Physical Activity In US Adolescents. J Am Diet Assoc. 2008; 108(2): 276-286; discussion 286.

21.Galisteo M, Duarte J, Zarzuelo A. Effects of Dietary Fibers on Disturbances Clustered in The Metabolic Syndrome. The Journal of nutritional biochemistry. 2008;19(2):71-84.

22.Adisti Fitriana dan Annis Catur. Hubungan Faktor Perilaku, Frekuensi Konsumsi Fast Food, Diet dan Genetika dengan Tingkat Kelebihan Berat Badan. 2013. Media Gizi Indonesia ; Vol. 9, 20-27.

23.Suhaema dan Herta. Consumption Patterns with Occurrence of Metabolic Syndrome in Indonesia. 2015. Jurnal Kesehatan Masyarakat Nasional : Vol. 9, No. 4.

24.Neva Arunika. Hubungan Pola Makan dan Aktivitas Fisik Terhadap Kejadian Overweight dan Obesitas pada Remaja. 2017. Karya Tulis Ilmiah Universitas Diponegoro. Semarang.

25.Adriani, M., \& Wirjatmadi, B. (2012). Peranan gizi dalam siklus kehidupan, edisi 1. Jakarta: Kencana Prenada Media Group.

26.Coplan, J.D., Wolk, S.I., Goetz, R.R., Ryan, N.D., Dahl, R.E., Mann, J.J., et al. 2000. Nocturnal growth hormone secretion studies in adolescents with or without major depression re-examined: integration of adult clinical follow-up data. Biol Psychiatry. 47(7): 594-604.

27.French, S.A., Harnack, L., and Jeffery, R.W. 2000. Fast food restaurant use among women in the pound of prevention study: Dietary, behavioral and demographic correlates. Obes. Relat. Metab. Disord., 24: 1353- 1359.

28.French, S.A., Neumark-Sztainer, D., Story, M., Fulkerson, J.A., and Hannan, P. 2001. Fast food restaurant use among adolescents: Associations with nutrient intake, food choices and behavioral and psychosocial variables. Int. J. Obes. Relat. Metab. Disord. 25: 1823-1833.

29.He, Q. and Karlberg, J. 2001. BMI in childhood and its association with height gain, timing of puberty, and final height. Pediatr Res. 49 (2): 244-251.

30.Haines, J., Neumark-Sztainer, D., Wall, M. and Story, M. 2007. Personal behavioral and environmental risk and protective factors for adolescent overweight. Obesity (Silver Spring). 15: 2748-2760.

31.Paeratakul, S., D.P. Ferdinand, C.M. Champagne, D.H. Ryan and G.A. Bray, 2003. Fast food consumption among U.S adult and children: Dietary and nutrient intake profile. J. Am. Diet. Assoc. 103: 1332-1338.

32.Fatmah and Achadi, E.A. 2015. Baseline survey on nutritional and health status of underfive children at poor communities in DKI Jakarta, Tangerang, and Bogor. MAKARA Kesehatan. 9 (2): 41-48.

33.Lussi W dan Fillah Fithra. Hubungan Tingkat Aktivitas Fisik, Kebiasaan Olahraga, Screen Time, dan Durasi Tidur dengan Kejadian Sindrom Metabolik pada Remaja Obesitas. 2016. Journal of Nutrition College: Vol. 5 ; 106-113.

34.Adisti Fitriana dan Annis Catur. Hubungan Faktor Perilaku, Frekuensi Konsumsi Fast Food, Diet dan Genetika dengan Tingkat Kelebihan Berat Badan. 2013. Media Gizi Indonesia ; Vol. 9, 20-27.

35.Koo H, Kim D, Chung H, Lee C. Association between metabolic syndrome and rate of lung function decline: a longitudinal analysis. Int J Tuberc Lung. Dis 2013;17:1507-14.

36.Lin W, Yao C, Wang H, Huang K. Impaired lung function is associated with obesity and metabolic syndrome in adults. obesity journal. 2006;14:1654. 
37.Siregar, M. Sindrom Metabolik [internet]. Medan: Repository Universitas Sumatera Utara; 2011 [diakses tanggal 14 Mei 2019]. Tersedia dari: http://repository.usu.ac.id/bitstream/123456789/25508/4/Chapter\%20II.pdf.

38.Leone N, Courbon D, Thomas F, Bean K, Jego B, Leynaert B, et al. Lung Function Impairment and Metabolic Syndrome: The Critical Role of Abdominal Obesity. American Journal of Respiratory and Critical Care Medicine. 2009;179:509-16.

39.Pramono A., (2007). Hubungan antara tingkat aktivitas fisik, kontribusi asupan energy dari fast food dan kebiasaan jajan dengan obesitas pada remaja. KTI Nutrition science program.

40.Bruscato NM, Vieria JL da C, do Nascimento NMR, et al. Dietary Intake is not associated to the Metabolyc Syndrome in Elderly Women. North American Journal of Medicine Sciences. 2010;2(4):182-188. doi: 10.4297//najms.2010.2182.

41.Antonia, Alex and Maria do Rosario. Validation and reliability of the Baecke questionnaire the evaluation of habitual physical activity in adult men. Rev Bras Med Esporte. 2003; Vol 9, No 3. 